\title{
Correct Posture of Human Beings for Pain Reduction using EMG Signals
}

\author{
[Dr. Pratibha Tyagi, Dr. A. S. Arora, Dr. Vikas Rastogi]
}

\begin{abstract}
Pain is an unpleasant feeling, which causes discomfort and can range from mild to chronic. It can be due to physical and emotional experience. About $80 \%$ of adults experience low back pain (LBP) at some point in their lifetimes. The purpose of this study is to record the SEMG signals of the human back to enlighten the correct posture to be maintained to reduce pain due to the different occupations, especially in the low back region. The spine especially lumbar vertebrae are considered as major elements to diagnose the lower back problems. These lower back disorders are mainly caused due to the various dynamic stresses developed by the compression of the lumbar vertebrae. Surface electrodes were used to record EMG of lower back, in the forward and backward direction from Yaxis, placed at different positions of vertebrae of the lumber region to have a view on the stress level of muscles involved in the movement. In this paper few features of EMG signals are analyzed using MATLAB.
\end{abstract}

The present work is a study on the knowledge of force/EMG relationship which is an experimental method to analyze force/stress on the lower back. The present research utilizes sEMG signals obtained from the lumbar region to establish the force/EMG relationship. In this research, force/EMG relationship in different sitting postures from the sagittal plane has been studied to adopt the proper posture to avoid stress. However, it is not possible to control or overcome all the factors to reduce low back pain but one can control the occupational low back pain by maintaining proper posture and by providing adequate support to the back. This research presents a technique for general quantitative analysis of musculoskeletal impact using sEMG through the evaluation of different sitting postures from the sagittal plane to assess the lower back muscles. Experimentally, EMG activity has been measured on L3 and L5 is statistically (significantly) different at different sitting posture with and without backrest and used to determine the minimum stress levels to move in the direction of pain reduction for better efficiency.

Keywords - Lumbar vertebrae, Back Posture, Low back pain, EMG signal

${ }^{1}$ Dr. Pratibha Tyagi, ${ }^{2}$ Dr. A.S. Arora, ${ }^{3}$ Dr. Vikas Rastogi

${ }^{1,2}$ Sant Longowal Institute of Engineering \& Technology, Longowal

Distt. Sangrur, Punjab, India

${ }^{3}$ Delhi Technological University

Delhi

\section{Introduction}

Low Back pain is most common among professionals/workers due to the occupation although it could be because of number of reasons. An immobile job or a desk job plays vital role towards the contribution of back pain, especially poor posture or prolonged sitting give birth to low back pain.Having a job that requires heavy lifting, pushing or pulling can lead to back injury and back pain.

The biomechanical risk factors for injury include prolonged sittings, awkward postures, excessive exertion, faulty equipment design etc. Due to the advancement in technologies, most of the professionals are forced to sit for longer time periods consequently they are more prone to low back pain. The intensity of low back pain is different for all individuals, which reduces their efficiencies. parentheses, following the example. Some components, such as multileveled equations, graphics, and tables are not prescribed, although the various table text styles are provided. The formatter will need to create these components, incorporating the applicable criteria that follow.

The back is the supporting organ of the human body. The human body is a complex structure and provides both mobility (bend and twist) and stability (remain upright all day). The normal spine has "S" shape when looked at from the side. Lower back, the lumbar region of the human spine, consists of five vertebras viz. L1-L5, which supports $60 \%$ of the body weight and permit movement. Lower back issues can put pressure on the lumbar spine nerves and create even stronger pain as the nerves become pinched or irritated from friction. LBP symptoms can be derived from many potential anatomic sources, such as nerve roots, muscle, fascial structures, bones, joints, intervertebral discs (IVDs), and organs within the abdominal cavity. The diagnostic evaluation of patients with LBP can be very challenging and requires complex clinical decision-making. Several clinical findings in LBP patients suggest that a relationship exists between the pain and morphological and mechanical abnormalities of the lumbar spine. A strong relationship of morphological abnormalities in the disc and a non uniform distribution of pressure in the intervertebral disc have been established. It suggests that mathematical modeling, biomechanical study and experimental study can give insight to problems related to Lower Back. The lower back disorders are mainly caused due to the various dynamic stresses developed by the compression of the lumbar vertebrae.

In the present research work, out of different diagnostic methods available for the diagnosis of low back pain, use of sEMG signals have been made to record the signals. 


\section{Biological Model of Vertebrae}

While going through the literature it is found that different researchers did a lot of studies in this field. Hauges and Nelson [1] have discussed the economic loss caused by the low-back pain to Industries. Ayari et.al. [2] evaluated the injury risk to vertebrae, when it exposed to vertical vibration.

Lower back anatomy as shown in Figure 1, is a wellengineered structure of bones, nerves, muscles, ligaments and tendons. With its complex and intricate construct, and the many stresses and force that can be placed on it through a trauma or even just daily activities, the lumbar spine is at risk for developing a number of painful conditions. The present study is only focused for the lumbar region having five vertebrae's L1 - L5 in the structure.

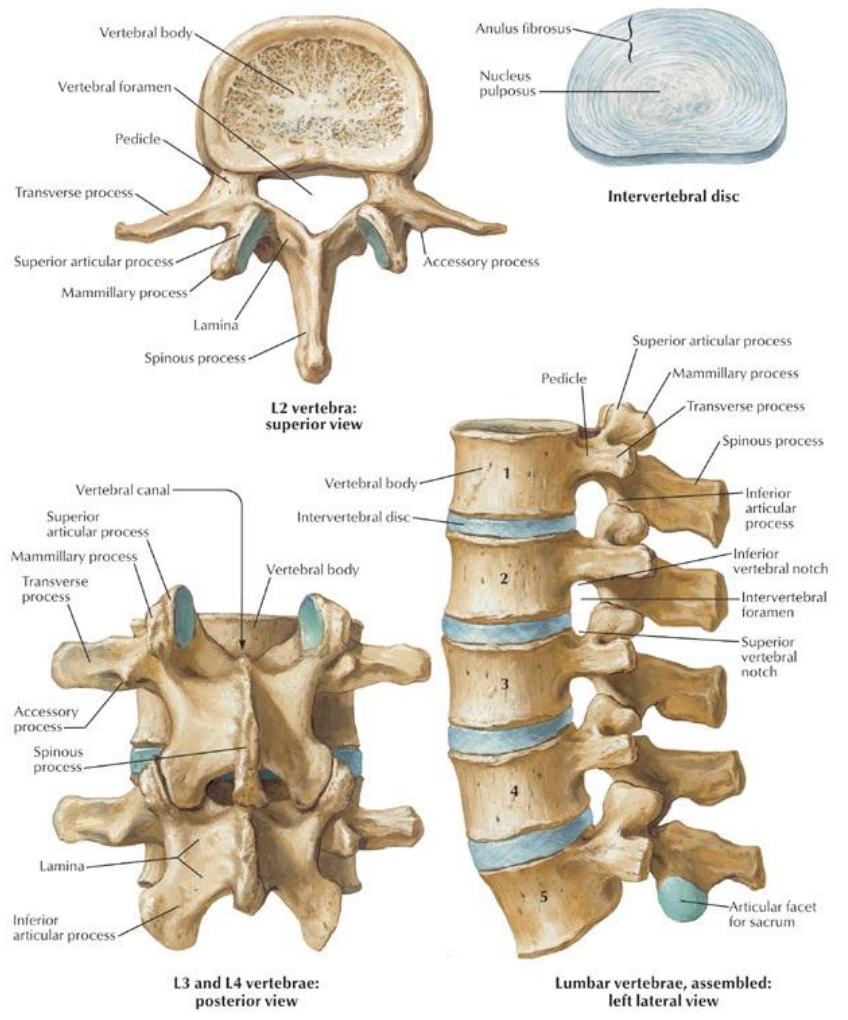

Figure 1: Structure of Lumbar spine [3]

\section{Experimental Setup}

MP 100 System is a complete and expandable data acquisition system that functions like an onscreen chart recorder, oscilloscope and $\mathrm{X} / \mathrm{Y}$ plotter, allowing recording, viewing, saving and printing the data. It includes all the necessary hardware and software required to turn any computer into a powerful data acquisition workstation specifically designed for life science applications [4]. Since the MP System takes advantage of the capabilities of the computer, it's as powerful as larger and more expensive data acquisition systems, but has a familiar, easy to use graphical interface. The MP System will reduce the equipment set-up time and increase the quality of results.

\section{A. Hardware Configurations}

In present setup, a USB based 16 channel data acquisition system has been used to record two channel of EMG from concerned muscles of neck. The two EMG amplifiers EMG100C have been used. These amplifiers allow variable gain setting and filtering options. abbreviations and acronyms the first time they are used in the text, even after they have been defined in the abstract. Electromyography signals of Lumbar region in different sitting postures

The small electric current, or signal, which comes from active muscles, is detected by sensors placed on the skin directly above the muscles. The strength and pattern of the signal is seen on a computer screen and the data is collected in a software program that is able to run various analyses of the data to create useful reports regarding muscle function. In order to study the behaviour of the lumbar region, Latissimus dorsi, the largest and superficial muscle of the back is is used for acquisition of EMG activity in this research work. The exact positioning of the electrodes is a critical task. For obtaining the EMG signals from the lumbar back at different vertebrae position, land marks of lumbar vertebras play very important role and are shown in Figure 2 (Low back, 2011).

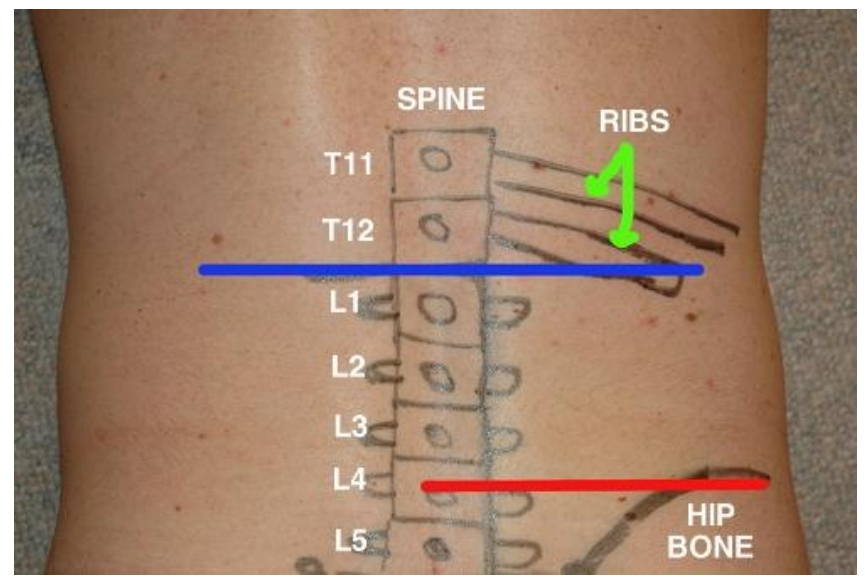

Figure 2: Location of Lumbar Vertebras [5]

In the present work, EMG signals were recorded by placing the sensors through two channels in forward/backward movement from the sagittal plane at different sitting postures from $75^{\circ}-120^{\circ}$ angles from the sagittal plane for L3 and L5 vertebral positions with back rest and without back rest. The acquisition and recording of data of one of the subject is shown in Figure 3 for one of the subject.

sEMG signals were recorded for a period of 60 seconds at L3 and L5 vertebral positions and are recorded in the Table 1 and Table 2 for four different positions $75^{\circ}, 90^{\circ}, 105^{\circ}$ and $120^{\circ}$ position of low back from sagittal plane for five different subjects. 


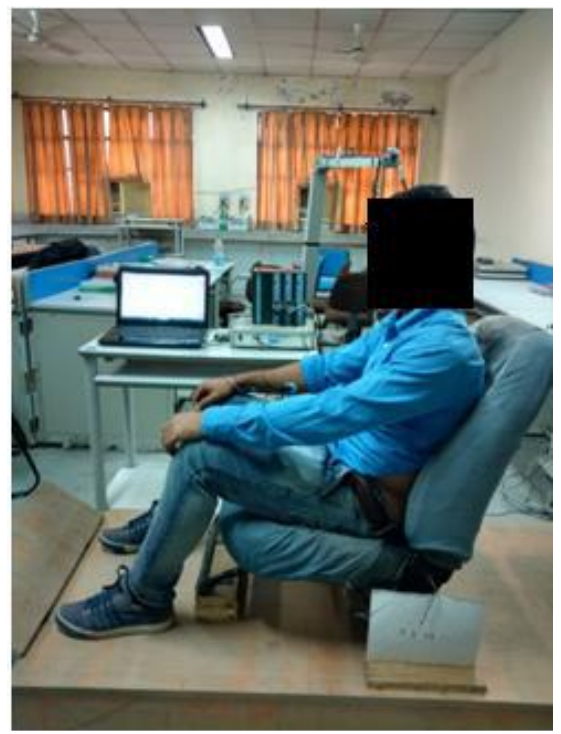

Figure 3: EMG signal recording using MP100 BIOPAC system

Table I. EMG values for different sitting postures WOR for L3 Vertebrae

\begin{tabular}{|c|c|c|c|c|}
\hline \multirow{2}{*}{ Subjects } & \multicolumn{4}{|c|}{ Location L3 } \\
\cline { 2 - 5 } & $\mathbf{7 5}^{\circ}$ & $\mathbf{9 0}^{\circ}$ & $\mathbf{1 0 5}^{\circ}$ & $\mathbf{1 2 0}^{\circ}$ \\
\hline Sub 1 & 0.17183 & $\mathbf{0 . 1 0 9 5 0}$ & 0.24583 & 0.32891 \\
\hline Sub 2 & 0.22200 & $\mathbf{0 . 2 1 3 8 3}$ & 0.41167 & 0.60992 \\
\hline Sub 3 & 0.19400 & 0.25517 & 0.30117 & $\mathbf{0 . 0 7 1 3 3}$ \\
\hline Sub 4 & 0.36633 & $\mathbf{0 . 3 2 3 2 2}$ & 0.37133 & 0.38317 \\
\hline Sub 5 & 0.11167 & $\mathbf{0 . 1 1 0 8 3}$ & 0.11086 & 0.11283 \\
\hline
\end{tabular}

Table II. EMG values for different sitting postures WOR for L 5 Vertebrae

\begin{tabular}{|c|c|c|c|c|}
\hline \multirow{2}{*}{ Subjects } & \multicolumn{4}{|c|}{ Location L5 } \\
\cline { 2 - 5 } & $\mathbf{7 5}^{\circ}$ & $\mathbf{9 0}^{\mathbf{}}$ & $\mathbf{1 0 5}^{\mathbf{}}$ & $\mathbf{1 2 0}^{\mathbf{}}$ \\
\hline Sub 1 & 0.07004 & $\mathbf{0 . 0 6 0 2 7}$ & 0.08002 & 0.09953 \\
\hline Sub 2 & 0.10620 & $\mathbf{0 . 0 1 9 4 2}$ & 0.02478 & 0.03920 \\
\hline Sub 3 & 0.02540 & 0.04862 & 0.02712 & $\mathbf{0 . 1 1 4 3 8}$ \\
\hline Sub 4 & 0.02457 & $\mathbf{0 . 0 2 4 3 5}$ & 0.02552 & 0.02733 \\
\hline Sub 5 & 0.00970 & $\mathbf{0 . 0 0 7 0 3}$ & 0.00790 & 0.00908 \\
\hline
\end{tabular}

[1] Hughes, R.E. and Nelson, N.A., (2008), "Estimating Investment Worthiness of an Ergonomic Intervention for Preventing Low Back Pain from Firm's Perspective," Applied Ergonomics, 30, pp.1-7.

[2] Ayari, H., Thomas, M., Dore, S., Serrus, O., (2009), "Evaluation of Lumber Vertebra Injury Risks to the Seated Human Body when Exposed to Vertical Vibration," Journal of Sound and Vibration.

[3] Lumbar vertebrae view accessed on July 15, 2018 , Retrieved from https://www.physio-pedia.com/images/0/08/Lumbar_vertebra.jpg

[4] Biopac Systems, "Acqknowledge Tutorial \& Demonstrations"

[5] Low Back accessed on May 10, 2011, Retrieved from https://www.pinterest.com/veselatodorova/massage/

About Author (s):

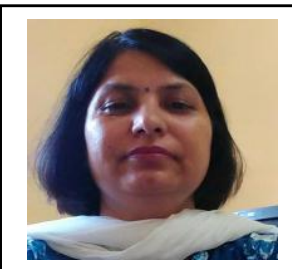

First Author

I, Pratibha Tyagi working in the Department of Electrical and Instrumentation engineering at Sant Longowal Institute of Engineering \& Technology Longowal District Sangrur, Punjab, India since 1993. I completed my M. Tech (Instrumentation) from National Institute of Technology (earlier as REC) Kurukshetra, Haryana, India. And did my Ph.D from SLIET Longowal. Presently Dr. Pratibha is working as Associate Professor at SLIET Longowal Sangrur, Punjab, India. Dr. Tyagi had presented/published around 15 papers in National/International conferences and Journals. Dr. A.S. Arora and Dr. Vikas Rastogi are working as Professor at SLIET Longowal, India and DTU Delhi, India respectively.

In this paper, lumbar region sEMG signal analysis has been done by calculating Average Absolute Mean (AAM) as tabulated in Table 1 and Table 2 without backrest position. It is clear from Table 1 and 2 that most of the time minimum position is occurring at an angle of $90^{\circ}$ sitting the sagittal plane while is minimum stress level

The authors wish to express profound gratitude to Director SLIET Longowal for providing them an opportunity to carry out this work in SLIET and sincere thanks are due for HOD (EIE) SLIET, Longowal for providing them the opportunity to carry out this work in Biomedical Research Lab of EIE Department, SLIET Longowal, India.

\section{References}

